\title{
MEASUREMENT AND EVALUATION OF FUNCTIONAL AND OPERATIONAL COEFFICIENTS OF HYDRAULIC SOLENOID VALVE PROTOTYPES USED FOR VARIABLE VALVE TIMING CONTROL IN COMBUSTION ENGINES
}

\author{
Marcin KALINOWSKI*, Zbigniew KAMIŃSKI* \\ *Faculty of Mechanical Engineering, Bialystok University of Technology, ul. Wiejska 45C, 15-351 Białystok, Poland \\ marcin8891@o2.pl, z.kaminski@pb.edu.pl
}

received 7 May 2020, revised 26 May 2021, accepted 2 June 2021

\begin{abstract}
This paper describes the engineering structure and functions of a typical solenoid valve used in hydraulic mechanisms that are based on variable camshaft timing (VCT). The main operating parameters and functional utility coefficients of hydraulic solenoid valves have been defined. Tests of 10 reference and 10 prototype valves were run on a test stand for a comparative assessment of both engineering concepts based on Welch and Mann-Whitney statistical tests of the mean values of designated coefficients. The studies identified differences between both designs, and the obtained research material was used as an input to improve the performance of the engineered concept. To perform a final evaluation of the effects that arise as a result of changes introduced to some functional-operational coefficients, additional tests are required to be run on an engine testbed. The applied test methodology may then be used for control and verification tests of the valves, which can further be used in VCT technology.
\end{abstract}

Key words: variable valve timing, hydraulic solenoid valve, prototype verification

\section{INTRODUCTION}

The variable valve timing (VVT) system allows for selecting valve timing parameters that are optimal for the actual load and speed of a combustion engine (Jankovic and Magner, 2002). The variable settings of camshaft phases change filling parameters of an engine cylinder, which adapt to time-varying loads (Jankovic and Magner, 2002). As a result, depending on the engine design and the number (1,2 or 4) of mounted valve timing control mechanisms, it is possible to reduce fuel consumption and exhaust emissions ( $\mathrm{HC}$ and NOx), as well as to increase the engine's power and torque (Chauvin and Petit, 2007; Gray, 1988; Stein et al., 1995).

Certain mechanism designs allow for control of the valve opening angle, valve lift or both (Dresner and Barkan, 1989; Ren, 2011; Stein et al., 1995). More advanced solutions include variable camshaft timing (VCT) mechanisms, using electronically controlled hydraulic actuators for the infinitely variable control of inlet and outlet time of the exhalation valve vs. the crankshaft. With the application of VVT technology, it is possible to control valve stroke, phase and valve timing at any point of the engine map, with the result of enhancing overall engine performance (Hong et al., 2004).

In the hydraulic subsystem of a typical VCT solution, it is a 4way, 3-position hydraulic solenoid valve that is responsible for appropriate engine timing. The electromagnet of a solenoid valve with infinitely variable opening changes is supplied with a pulse-width modulation (PWM) voltage signal. The electronically controlled solenoid valve redirects pressurised oil from the engine lubrication system to the actuator to move or retract the camshaft angles (rotation of a chain or belt pulley) vs. the crankshaft (Gray, 1988).

Proper action of the hydraulic solenoid valve is highly significant for VCT operation and thus for engine performance. Therefore, at the final stage of the production process, solenoid valves are submitted to control tests (Kosuke et al., 2006) to verify the compliance of features and parameters of a pre-determined number of valves with the requirements set in the standard. In the case of prototype solenoid valves, they become subject to qualification tests (ISO16750-1, 2006), the goal of which is a comprehensive overview and evaluation of technical and operational features of the product to make a decision concerning either the manufacture of an informative or sample batch or the release of series production of a new solenoid valve.

This paper describes the engineering structure and functions of a typical solenoid valve used in hydraulic mechanisms of VCT, discussing its major operational parameters and functionaloperational indices. The method and the test stand used for the measurement and assessment of the indices are also presented with regards to necessary control and qualification tests. The tests run on the test stand have been used for a comparative evaluation of the prototype design of a hydraulic solenoid valve offered for Aftermarket customers, designed and assembled in SMP Poland company and a reference solenoid valve that is used, for example, in Ford V8 combustion engines with $5.4 \mathrm{~L}$ capacity in 2004-2010. 


\section{THE OPERATING PRINCIPLE OF SOLENOID VALVE PARAMETERS AND FUNCTIONAL-OPERATIONAL COEFFICIENTS}

A solenoid valve consists of two main sub-assemblies (shown in Fig. 1): an electromagnet (an electromagnetic subsystem) and a hydraulic directional spool valve (a mechanical hydraulic subsystem). The solenoid valve controls the oil stream at its outlet, depending on the supplied voltage signal UPWM, which is determined by PWM during the period in which the electric energy is supplied to the electromagnet. The coil in the electric circuit induces current, $i(t)$, which is directly transformed into force, $F_{M}(t)$, generated in the electromagnetic circuit and pushing out the valve piston.

To ensure simultaneous motion of the electromagnet piston and the valve spool, a spring is mounted in the solenoid valve, and it performs the function of pushing the piston face to the slide face. Depending on the applied forces acting on the mechanical subsystem (piston, spool and spring), there is movement, $x(t)$, of the spool of the 4-way, 3-position hydraulic directional valve. The movement of the spool in the valve body changes the direction and flows of volumetric oil streams, $q_{v A}(t)$ and $q_{v B}(t)$, supplied from the engine's oil system, on the hydraulic valve outlets.

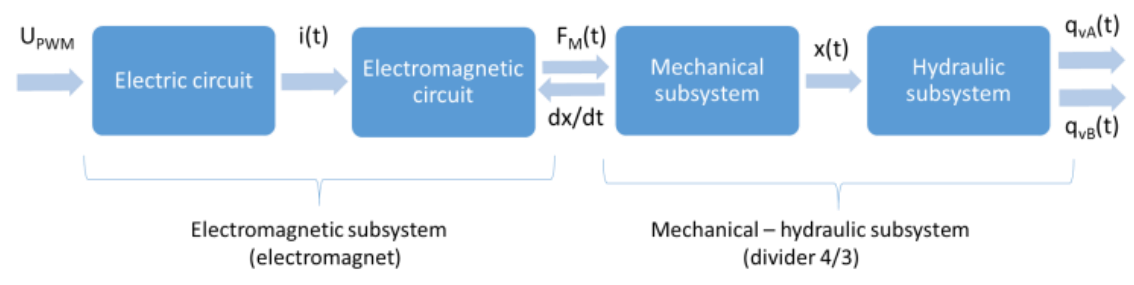

Fig. 1. Flowchart of a hydraulic solenoid valve

a)

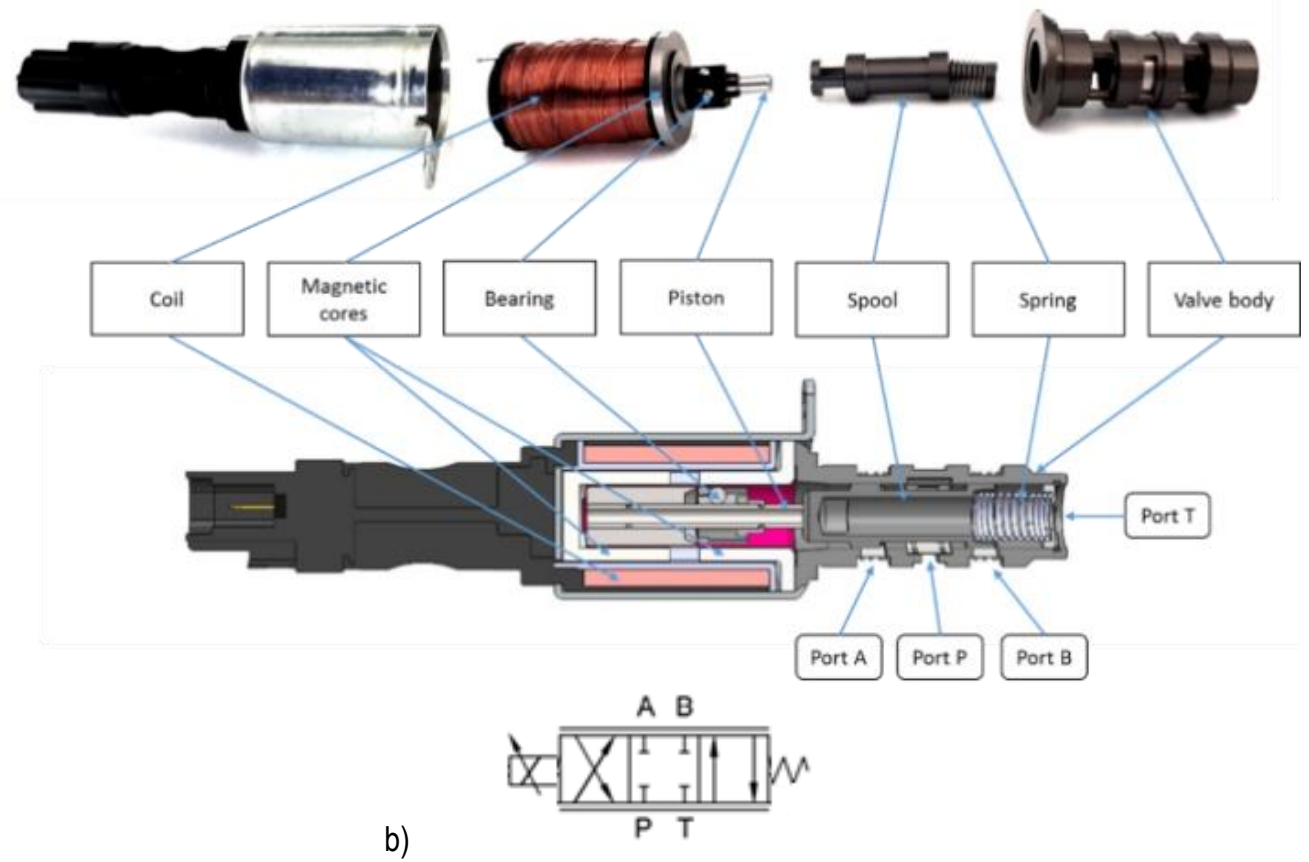

Fig. 2. A cross-section, illustrating the solenoid valve structure (a) and graphic representationl of the proportional electrohydraulic solenoid valve (b)

A cross section of a typical solenoid valve used in VCT systems is shown in Fig. 2. In the initial state, when the current induced in the coil is not so high as to generate a force capable of shifting the electromagnet piston, the spool of the hydraulic solenoid valve is located on the left extreme position, pushed by the force of the return spring. In this case, ports $P$ and $A$ and $B$ and $T$ are connected, and their order is shown in Fig. 2. A maximum oil stream, $q_{v A}$, flows under pressure from the supply port $P$ to the outlet port $A$, connected with the actuator's chamber (outflow), while oil from the actuator's other chamber flows to port B and, farther, to port $T$, connected with the engine's oil sump (runoff).
Increasing the fill factor in the PWM signal brings an increase of coil current and a proportional decrease of flows $q_{v A}(t)$ and $q_{v B}(t)$ until their complete disappearance. In this state, corresponding to the valve spool neutral position, ports $A$ and $B$ are cut off from ports $P$ and $T$, while the angular position of the camshaft vs. the engine's crankshaft is not changed. This situation is observed at a constant load for a combustion engine, e.g. when constant crankshaft speed is observed. Regarding the valve design, when the valve spool is in a neutral position, there is positive overlap. Further increases of PWM signal fill factor open the passage between ports $P$ and $B$ and $A$ and $T$ (a change of the flow direction to the actuator's chambers) 
to the upper control limit, in which the generated electromagnetic force is large enough for the piston to move the spool of the solenoid valve to the other extreme position, where maximum qvi flow value can be obtained. When the solenoid valve is checked on test stands, the outlet ports, $A$ and $B$, are usually connected.

The main functional-operational parameters, which are important for the assessment of correct solenoid valve operation, include the following:

- The values of volumetric flow, quLc and quric, in extreme spool positions, are expressed in $1 / \mathrm{min}$; for qvLc, it is $(P \rightarrow A \rightarrow B \rightarrow T)$ flow at low control current, while for quric, it is $(P \rightarrow B \rightarrow A \rightarrow T)$ flow at high control current (see Fig. 3a):

$q_{v L C}=q_{V}(I=0.1 A)$

$q_{v H i C}=q_{V}(I=1.3 \mathrm{~A})$

- The values of pressure, pLC and pHic, at port P inlet in extreme spool positions, for PLc; it is the pressure value at low control current to the solenoid valve, $(I=0.1 \mathrm{~A})$ for $p_{L C}$ and $(I=1,3 \mathrm{~A})$ for pHic (see Fig. 3e):

$p_{L C}=p(I=0.1 A)$

$p_{H i C}=p(I=1.3 \mathrm{~A})$

- The width of the neutral spool shift, defined as the absolute difference of current values at the time when flow drops to 0.5 $\mathrm{l} / \mathrm{min}$ and at the time when flow rises above $0.5 \mathrm{l} / \mathrm{min}$, is another parameter. This parameter is measured both with increasing, $\Delta I_{H i n c}$, and decreasing, $\Delta I_{H d e c}$, control current (see Fig. $3 \mathrm{~b}$ ):

$\Delta I_{\text {Hinc }}=I_{2}-I_{1}$

$\Delta I_{\text {Hdec }}=I_{3}-I_{4}$

- The mean current value, $\mathrm{lH}$, needed to maintain the neutral spool position, is another parameter, which is calculated as an arithmetic mean of the current as flow drops below $0.5 \mathrm{l} / \mathrm{min}$ and flow increases above $0.5 \mathrm{l} / \mathrm{min}$, with current increase, lHinc, and current decrease, lidec, respectively (see Fig. 3b):

$I_{\text {Hinc }}=\frac{I_{1}+I_{2}}{2}$

$I_{\text {Hdec }}=\frac{I_{3}+I_{4}}{2}$

- The value of volumetric flow, qMLF, at the current level, which maintains the neutral spool position, is another parameter that functions as a measure of leakage flow; this is measured increase, qMLFinc, and decrease, qMLFdec, in control current (see Fig. 3b):

$q_{\text {MLFinc }}=q_{V}\left(I_{\text {Hinc }}\right)$

$q_{\text {MLFdec }}=q_{V}\left(I_{\text {Hdec }}\right)$

- The value of pressure, pMLF, at the current level, which maintains the neutral spool position, is another parameter that functions as the measure of leakage; this is measured with increase, qMLFinc, and decrease, qmLFdec, in control current (see Fig. 3e): $p_{\text {MLFinc }}=p\left(I_{\text {Hinc }}\right)$

$p_{\text {MLFdec }}=p\left(I_{\text {Hdec }}\right)$

- The $\left.\Delta\right|_{\text {Hist }}$ parameter functions as the hysteresis, i.e. the difference of current values with the spool moving to the left, $\left.\Delta\right|_{\text {Histt, }}$ or to the right, $\Delta \mathrm{l}_{\text {HistR, }}$, for the same flow value of $2 \mathrm{l} / \mathrm{min}$. (see Figure 3c):

$\Delta I_{\text {HistL }}=I_{6}-I_{5}$

$\Delta I_{\text {HistR }}=I_{8}-I_{7}$

- The slope of the flow characteristic curve during changes of the directional valve state, defined as directional coefficients $K_{A}$ and $\mathrm{K}_{\mathrm{B}}$ of the regression line equation $\mathrm{qv}_{\mathrm{v}}=\mathrm{K} \cdot \mathrm{l}+\mathrm{C}$ for flows in the range from $0.8 \mathrm{l} / \mathrm{min}$ to $2.8 \mathrm{l} / \mathrm{min}$, during increase (inc) and decrease (dec) of the control current I (see Fig. 3d):

$q_{\text {vAinc }}=K_{\text {Ainc }} I+C_{\text {Ainc }}$ from $0.8 \mathrm{l} / \mathrm{min}<q_{\text {vinc }}<$ $2.8 \mathrm{l} / \mathrm{min}$ for $I<0.5 \mathrm{~A}$

$q_{v \text { Binc }}=K_{\text {Binc }} I+C_{\text {Binc }}$ from $0.8 \mathrm{l} / \mathrm{min}<q_{v i n c}<$ $2.8 \mathrm{l} / \mathrm{min}$ for $\mathrm{I}>0.5 \mathrm{~A}$

$q_{\text {vadec }}=K_{\text {Adec }} I+C_{\text {Adec }}$ from $0.8 \mathrm{l} / \mathrm{min}<q_{\text {vinc }}<$ $2.8 \mathrm{l} / \mathrm{min}$ for $\mathrm{I}>0.5 \mathrm{~A}$

$q_{v \text { Bdec }}=K_{\text {Bdec }} I+C_{\text {Bdec }}$ from $0.8 \mathrm{l} / \mathrm{min}<q_{v i n c}<$ $2.8 \mathrm{l} / \mathrm{min}$ for $I<0.5 \mathrm{~A}$

The adequacy of the linear regression model can be tested by the coefficient of determination (Walpole et al., 2012), computed both when the control current is increased, $R_{2 A i n c}, R_{2 B i n c}$, and decreased, $R_{2 A d e c}, R_{2 B d e c}$, respectively, for ports $A$ and $B$.

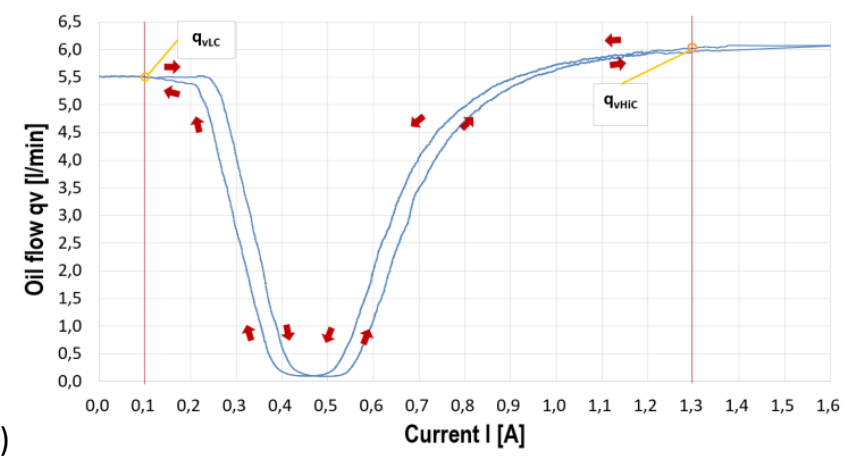

a)

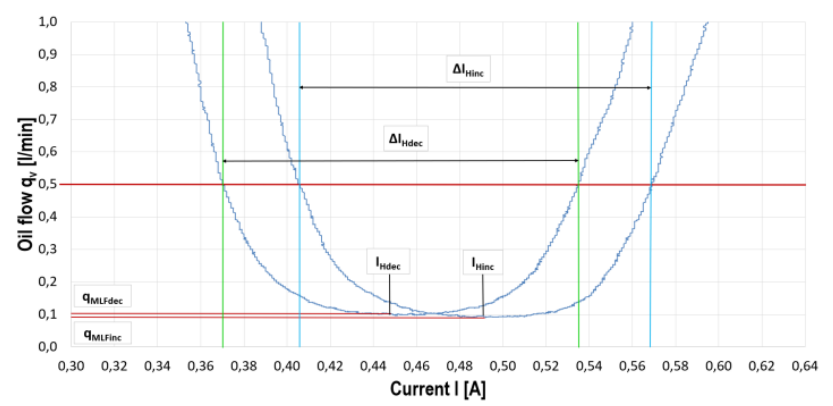

b) Current I [A] 
c)

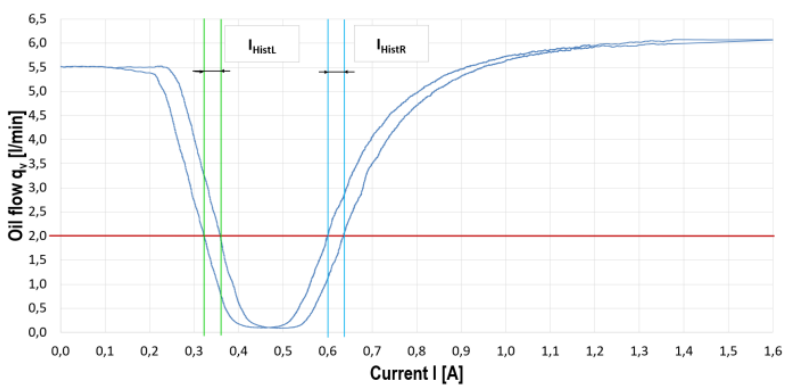

d)
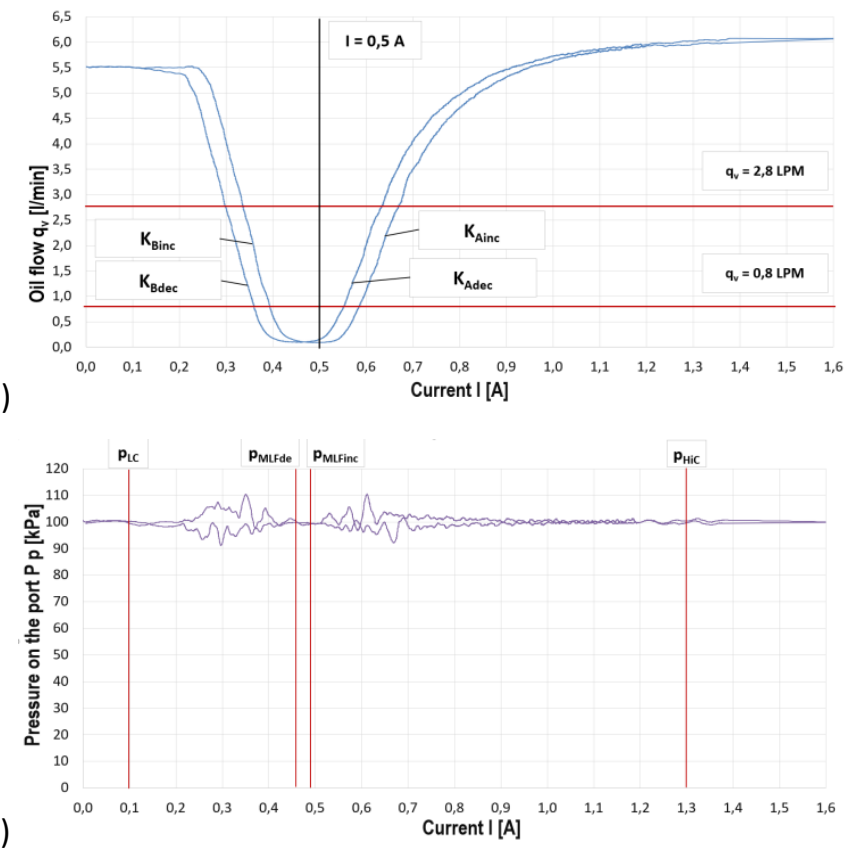

Fig. 3. Oil flow and pressure characteristics in the function of current graphical interpretation of measured parameters

\section{TEST STAND AND TEST PROCEDURE}

Test stands for hydraulic solenoid valves are types of equipment with various purposes and they differ in their complexities. To check the correct operation of VCT systems, they use simplified models of an internal combustion engine, imitating the target operating conditions. This type of tester uses original combustion engine heads, in which the camshaft is driven by an electric motor and the solenoid valve is connected to a hydraulic power supply, mapping the operating parameters of the lubrication system (Ren, 2011). By simulating the operation of a hydraulic solenoid valve through appropriate control, feedback is obtained about the correct operation of the entire VCT system on which the solenoid valve acts.

Specialist testers are used to check the functional and operational parameters of the hydraulic solenoid valves themselves; the tested valve is mounted to a socket reflecting the original socket in the engine body. By setting oil pressure and controlling the PWM signal, parameters describing valve operation in steady and transient states can be determined. The tester manufactured by INA [8] is an example of such a device. The following parameters can be measured:

- Coil resistance
- Coil inductance

- Insulation resistance

- Magnet force

- Magnet stroke

- Oil pressures

- Oil temperatures

- Oil flow rates

- Duty cycle

- Electrical current.

The following characteristics are determined from the measured parameters:

- Maximum magnet stroke

- Magnet force vs. magnet stroke for a given electrical current

- Magnetic force hysteresis

- Oil volumetric flow in the end positions

- Oil volumetric flow in a closed position (leakage)

- Electrical current in a closed position

- Hysteresis

- Pressure differences

Hydraulic solenoid valves were examined on a test stand manufactured by a US supplier on a special order (see Fig. 4). The test stand has similar functionality to the INA stand, except for the possibility to measure a magnet force.

Fig. 5 presents a schematic diagram of the experimental device. The device consists of a VCT solenoid valve controller, a data acquisition system and a hydraulic driving unit. The hydraulic system is supplied with oil from the gear pump (1), with a capacity of 17.4 $\mathrm{I} / \mathrm{min}$; the pressure is set using the relief valve (2) (2700 kPa max.). The proportional reduction valve (3) is intended to reduce pressure in the hydraulic circuit of the tested VCT solenoid valve (6) in the $103-620 \mathrm{kPa}$ range. Directly before the solenoid valve (6), mounted in the test seat, a 3-way, 2-position directional control valve is mounted (5). During tests, the directional control valve redirects oil to port $\mathrm{P}$ of the tested solenoid valve and, when the test is completed, oil is redirected to the tank. Oil flow through the tested solenoid valve is measured using a flowmeter (4), with a $0.1-15 \mathrm{l} / \mathrm{min}$ scale range and $0.3 \%$ accuracy. Oil pressure at selected areas of the hydraulic system is measured using pressure transducers (8 and 9 ), with a measurement scope to $1000 \mathrm{kPa}$ and $0.1 \%$ accuracy. Oil temperature is measured using a transducer (7), with a PT100 sensor with $\mathrm{a} \pm 0.33^{\circ} \mathrm{C}$ accuracy.

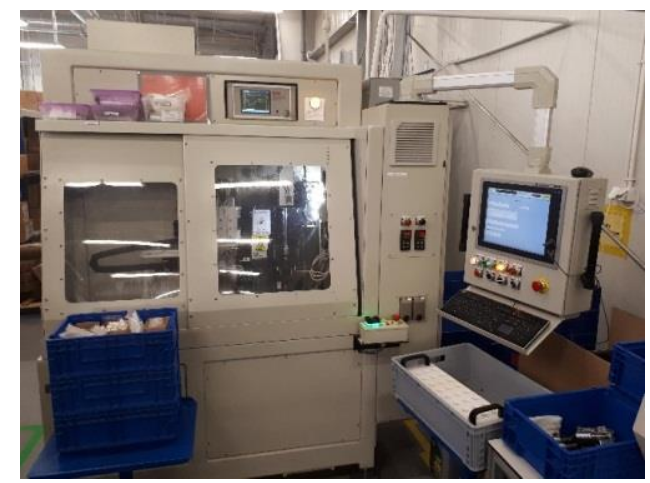

Fig. 4. Test stand for testing hydraulic solenoid valves 
The coil of the tested solenoid valve is connected to a PWM generator (12), controlled by a control unit (13), integrated with the acquisition system of output signals from the pressure transducers (8 and 9), temperature transducer (7), current transducers (11) and coil resistance transducers (10). Test conditions and parameters can be changed from the control panel (14).

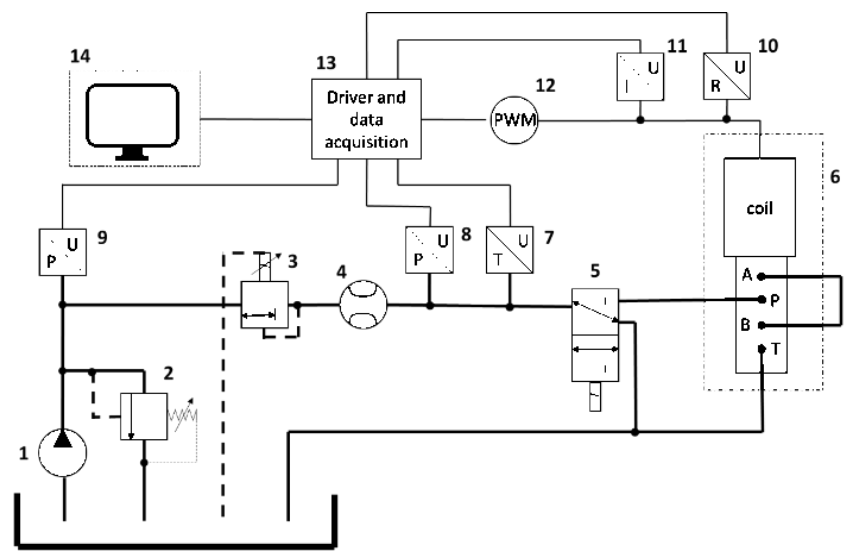

Fig. 5. Schematic diagram of hydraulic solenoid valve test stand: 1 - hydraulic pump, 2 - relief valve, 3 - reduction valve, 4 - flowmeter, 5 - 3-way 2-position directional control valve, 6 - tested hydraulic

solenoid valve, 7 - transducer with PT100 temperature sensor, 8 and 9 - pressure transducers, 10 - coil resistance transducer, 11 - current transducer, 12 - PWM generator, 13 - control unit, 14 - operator panel

When the solenoid valve is checked on test stands, the outlet ports, $A$ and $B$, are connected. The control unit enables the performance of measurement tests in the automatic mode, in which the full operational cycle of a VCT solenoid valve is run with variable control. The control unit provides a PWM signal with a variable PWM fill factor, causing a change in the current induced in the valve coil. Initially, the PWM fill factor grows in such a way that the current value changes from $0 \mathrm{~A}$ to $1.6 \mathrm{~A}$ and then it decreases again. The rate of increasing coil current is specified in the test station programme. To change the current from $0 \mathrm{~A}$ to $1.6 \mathrm{~A}$, the test stand has $11 \mathrm{~s}$, and thereafter it has the subsequent $11 \mathrm{~s}$ to decrease from $1.6 \mathrm{~A}$ to $0 \mathrm{~A}$. Depending on the rise time, we can observe different flow characteristics in the part where the valve is closing or opening port $\mathrm{A}$ or $\mathrm{B}$. The heat conditions during the test are close to real solenoid valve application conditions, i.e. the temperature of the mounting seat for the solenoid valve and of the flowing oil is $90 \pm$ $5^{\circ} \mathrm{C}$. Changes and control of settings are possible by the addition of input data to the device's control software via the control panel.

An integrated part of the test stand is control unit software, designed by the manufacturer of the unit. Based on recorded time histories of oil pressure and flow through the studied solenoid valve, it is possible to determine its proper operating condition, verify whether the valve responds properly to variable control and check if there are no unwanted leaks on the valve. The control unit software also calculates the required functional-operational parameters, defined in Section 2. The advantage of this test stand and software is their universality, i.e. the ability to test solenoid valves with various designs, ease of defining parameters and their tolerance fields, visibility of results and the ability to automate quality control.

An example screenshot presenting measured pressure characteristics of port $\mathrm{P}$ (celadon green), with oil flows (yellow) as a function of current and the window with measured results for key solenoid valve coefficients, is shown in Fig. 6.

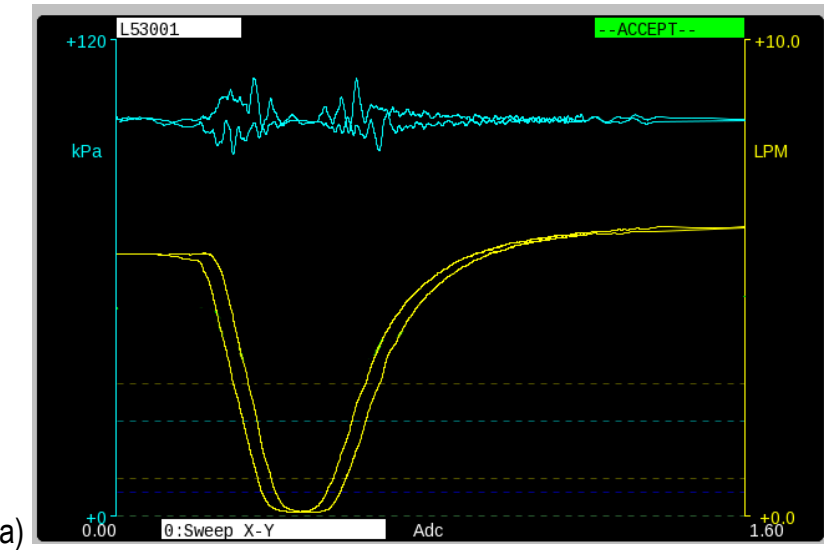

b)

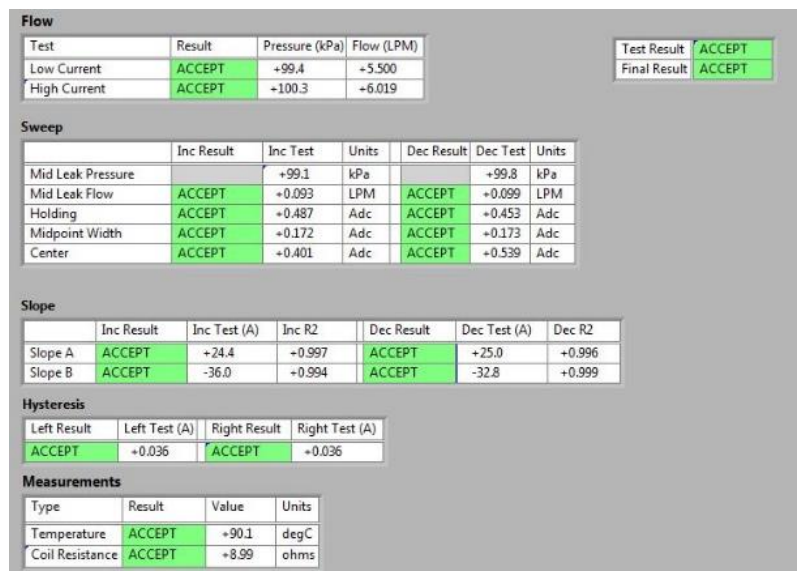

Fig. 6. Examples of hydraulic solenoid valve runs, measured by a tester (a) and the measured results of key solenoid valve parameters (b)

\section{TEST COURSE AND RESULTS}

Reference hydraulic solenoid valves, operating in the variable cam timing (VCT) system, manufactured by Ford, original equipment $(\mathrm{OE})$ and prototype valves, for which the design is based on the reference products, were selected for tests. See Fig. 7 for the photos of both solenoid valves. The main difference between them is that they use different materials and process parameters. The electromagnet designs that have been selected as prototypes have different number of turns in coil and varying core properties.

The goal of the tests was to evaluate the technical and operational features of the new product. The study programme included automatic tests, runs on a test stand described in the previous section and comprises the reference and prototype solenoid valves.

The results of the tests, performed for 10 of each solenoid valve type enabled us to develop values of functional-operational coefficients. 
a)

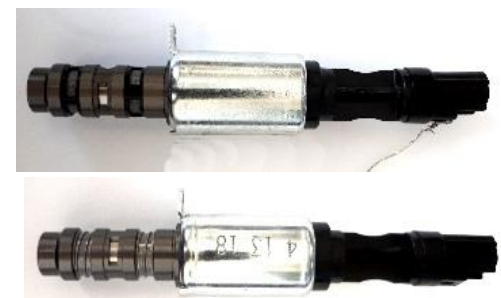

b)

Fig. 7. A comparison of hydraulic solenoid valves. Ford's design (a) and a prototype solenoid valve design (b)
Then mean values and standard deviations were calculated for particular coefficients. The D'Agostino bilateral skewness test (D'Agostino et al., 1990), recommended for low-number samples $(n>8)$, was applied to check the normality of the distribution of particular coefficients. p-values were computed based on the test statistic $\mathrm{sZ}\left(\sqrt{\mathrm{b}_{1}}\right)$, which is the normal approximation to sample skewness, $\sqrt{b_{1}}[14]$. In the majority of cases (Tab. 1), no reasons were found to reject the hypothesis of distribution normality at the $a=0.05$ ( $p$-value $>0.05$ ) significance level.

Tab. 1. The results from tests and D'Agostino normality test for 10 reference solenoid valves from Ford and 10 solenoid valve prototypes

\begin{tabular}{|c|c|c|c|c|c|c|c|c|c|c|c|}
\hline \multirow{2}{*}{\multicolumn{3}{|c|}{ Functional charasteristics }} & \multirow{4}{*}{$\begin{array}{l}\text { Unit } \\
\mathrm{kPa} \\
\end{array}$} & \multicolumn{4}{|c|}{ Reference valves } & \multicolumn{4}{|c|}{ Prototype valves } \\
\hline & & & & \multirow[b]{2}{*}{ Average } & \multirow{2}{*}{$\begin{array}{l}\text { Standard } \\
\text { deviation }\end{array}$} & \multicolumn{2}{|c|}{ Normality test D'Agostino } & \multirow[b]{2}{*}{ Average } & \multirow{2}{*}{$\begin{array}{l}\text { Standard } \\
\text { deviation }\end{array}$} & \multicolumn{2}{|c|}{ Normality test D'Agostino } \\
\hline & . & & & & & p-value & $\begin{array}{c}\text { Normal } \\
\text { distribution }\end{array}$ & & & p-value & $\begin{array}{c}\text { Normal } \\
\text { distribution }\end{array}$ \\
\hline \multirow{4}{*}{ Flow } & Pressure at Low Current & $p_{\mathrm{LC}}$ & & 100.1 & 0.400 & 0.12102 & YES & 100.3 & 0.320 & 0.47581 & YES \\
\hline & Flow at Low Current & $q_{v L C}$ & $\mathrm{I} / \mathrm{min}$ & 5.531 & 0.069 & 0.28146 & YES & 6.061 & 0.263 & 0.16469 & YES \\
\hline & Pressure at High Current & $\mathbf{p}_{\text {HiC }}$ & $\mathrm{kPa}$ & 100.2 & 0.271 & 0.22068 & YES & 100.3 & 0.369 & 0.02372 & NO \\
\hline & Flow at High Current & $\mathbf{q}_{\text {Hic }}$ & $\mathrm{l} / \mathrm{min}$ & 6.019 & 0.201 & 0.19119 & YES & 6.521 & 0.207 & 0.18439 & YES \\
\hline \multirow{4}{*}{$\begin{array}{l}\text { Sweep during } \\
\text { increasing } \\
\text { current }\end{array}$} & Mid Leak Pressure & $\mathbf{p}_{\text {MLPinc }}$ & $\mathrm{kPa}$ & 99.5 & 0.504 & 0.30709 & YES & 99.5 & 0.126 & 0.50000 & YES \\
\hline & Mid Leak Flow & $\mathbf{q}_{\text {MLFinc }}$ & $\mathrm{I} / \mathrm{min}$ & 0.113 & 0.019 & 0.22871 & YES & 0.169 & 0.041 & 0.04255 & NO \\
\hline & Holding current & $I_{\text {HCinc }}$ & Adc & 0.490 & 0.004 & 0.34267 & YES & 0.524 & 0.018 & 0.12583 & YES \\
\hline & Midpoint Width & $\Delta \mathbf{I}_{\text {HCinc }}$ & Adc & 0.174 & 0.009 & 0.09657 & YES & 0.211 & 0.018 & 0.37345 & YES \\
\hline \multirow{4}{*}{$\begin{array}{l}\text { Sweep during } \\
\text { decreasing } \\
\text { current }\end{array}$} & Mid Leak Pressure & $\mathbf{p}_{\text {MLPdec }}$ & $\mathrm{kPa}$ & 100.0 & 0.359 & 0.00658 & NO & 100.1 & 0.322 & 0.35549 & YES \\
\hline & Mid Leak Flow & $\mathbf{q}_{\text {MLfdec }}$ & $\mathrm{I} / \mathrm{min}$ & 0.117 & 0.021 & 0.19481 & YES & 0.173 & 0.040 & 0.07439 & YES \\
\hline & Holding current & $I_{\text {HCdec }}$ & Adc & 0.455 & 0.005 & 0.21737 & YES & 0.488 & 0.016 & 0.21529 & YES \\
\hline & Midpoint Width & $\Delta \mathrm{I}_{\text {HCdec }}$ & Adc & 0.177 & 0.010 & 0.26571 & YES & 0.213 & 0.020 & 0.31029 & YES \\
\hline \multirow{6}{*}{$\begin{array}{l}\text { Slope during } \\
\text { increasing } \\
\text { current }\end{array}$} & \multirow{2}{*}{ Slope A } & $\mathrm{K}_{\text {Ainc }}$ & $\mathrm{I} /(\min \cdot \mathrm{Adc})$ & 26.0 & 1.146 & 0.37679 & YES & 33.6 & 3.715 & 0.22474 & YES \\
\hline & & $C_{\text {Ainc }}$ & $\mathrm{I} / \mathrm{min}$ & 14.70 & 0.631 & 0.48243 & YES & 14.4 & 0.681 & 0.47579 & YES \\
\hline & R2 - slope A & $\mathbf{R}_{\text {KAinc }}^{2}$ & - & 0.995 & & & & 0.990 & & & \\
\hline & \multirow{2}{*}{ Slope B } & $K_{\text {Binc }}$ & $\mathrm{I} /(\min \cdot \mathrm{Adc})$ & 35.8 & 0.986 & 0.28271 & YES & 30.1 & 3.587 & 0.46642 & YES \\
\hline & & $\mathrm{C}_{\text {Binc }}$ & $\mathrm{I} / \mathrm{min}$ & -13.4 & 0.559 & 0.50000 & YES & -19.8 & 0.694 & 0.45970 & YES \\
\hline & R2 - slope B & $\mathbf{R}_{\mathrm{KBinc}}^{2}$ & - & 0.995 & & & & 0.996 & & & \\
\hline \multirow{6}{*}{$\begin{array}{c}\text { Slope during } \\
\text { decreasing } \\
\text { current }\end{array}$} & \multirow{2}{*}{ Slope A } & $K_{\text {Adec }}$ & $\mathrm{I} /(\min \cdot \mathrm{Adc})$ & 27.9 & 1.926 & 0.40153 & YES & 40.9 & 5.959 & 0.25523 & YES \\
\hline & & $\mathrm{C}_{\text {Adec }}$ & $1 / \min$ & 12.6 & 0.704 & 0.50000 & YES & 11.9 & 0.702 & 0.47762 & YES \\
\hline & R2 - slope A & $\mathbf{R}_{\text {KAdec }}^{2}$ & - & 0.995 & & & & 0.989 & & & \\
\hline & \multirow{2}{*}{ Slope B } & $K_{\text {Bdec }}$ & $\mathrm{I} /(\min \cdot \mathrm{Adc})$ & 33.3 & 1.066 & 0.31149 & YES & 27.0 & 2.922 & 0.44216 & YES \\
\hline & & $C_{\text {Bdec }}$ & $\mathrm{l} / \mathrm{min}$ & -13.1 & 0.694 & 0.45536 & YES & -21.8 & 0.681 & 0.28707 & YES \\
\hline & R2 - slope B & $\mathbf{R}_{\text {KBdec }}^{2}$ & - & 0.997 & & & & 0.996 & & & \\
\hline \multirow{2}{*}{ Hysteresis } & Left & $\Delta \mathrm{I}_{\text {Histl }}$ & Adc & 0.037 & 0.001 & 0.26538 & YES & 0.038 & 0.004 & 0.35467 & YES \\
\hline & Right & $\Delta \mathbf{I}_{\text {HistR }}$ & Adc & 0.037 & 0.003 & 0.37865 & YES & 0.042 & 0.006 & 0.43033 & YES \\
\hline \multicolumn{2}{|c|}{ Temperature } & & $\operatorname{deg} C$ & 90.5 & 0.236 & 0.00975 & $\mathrm{NO}$ & 90.7 & 0.136 & 0.09773 & YES \\
\hline \multicolumn{2}{|c|}{ Coil resistance } & & Ohms & 8.854 & 0.077 & 0.02911 & NO & 9.144 & 0.408 & 0.00497 & NO \\
\hline
\end{tabular}

Significance studies of mean value differences were performed for the same coefficient to achieve a comparative assessment of both solenoid valve designs. Due to ambiguous normality test results, both the Welch's t-test (for population of normal distribution and different variances) (Kanji, 2006; Welch, 1947) and the nonparametric Mann-Whitney U-test, also called the Mann-WhitneyWilcoxon test (MWW) (Kanji, 2006; Marks et al., 2016), were used for tests of equality of means. Test statistical values and their critical values were designated for both t-test and the U-test, respectively. The test statistics enables calculating the associated probability $\mathrm{p}$ values, which were then compared with the $a=0.05$ significance level. If $p>a$, then it was assumed that there were no reasons to reject the null hypothesis, $\mathrm{H}_{0}$, about the equality of means. If $p \leq a$, an alternative hypothesis, $H_{1}$, was assumed concerning the significance of the differences between the means of particular coefficients. Tab. 2 presents the results of probability calculations ( $p$ values) and test results.

The results of both tests demonstrated statistically significant differences between the coefficients obtained for both groups of solenoid valves, i.e. reference and prototype products. The Welch test enabled identifying 14 differences out of 20 analysed coefficients. On the other hand, the MWW test, besides the same 14 coefficients, also demonstrated a significant difference in solenoid resistance. 
Tab. 2. Statistical analysis for 10 reference solenoid valves from Ford and 10 prototype solenoid valves

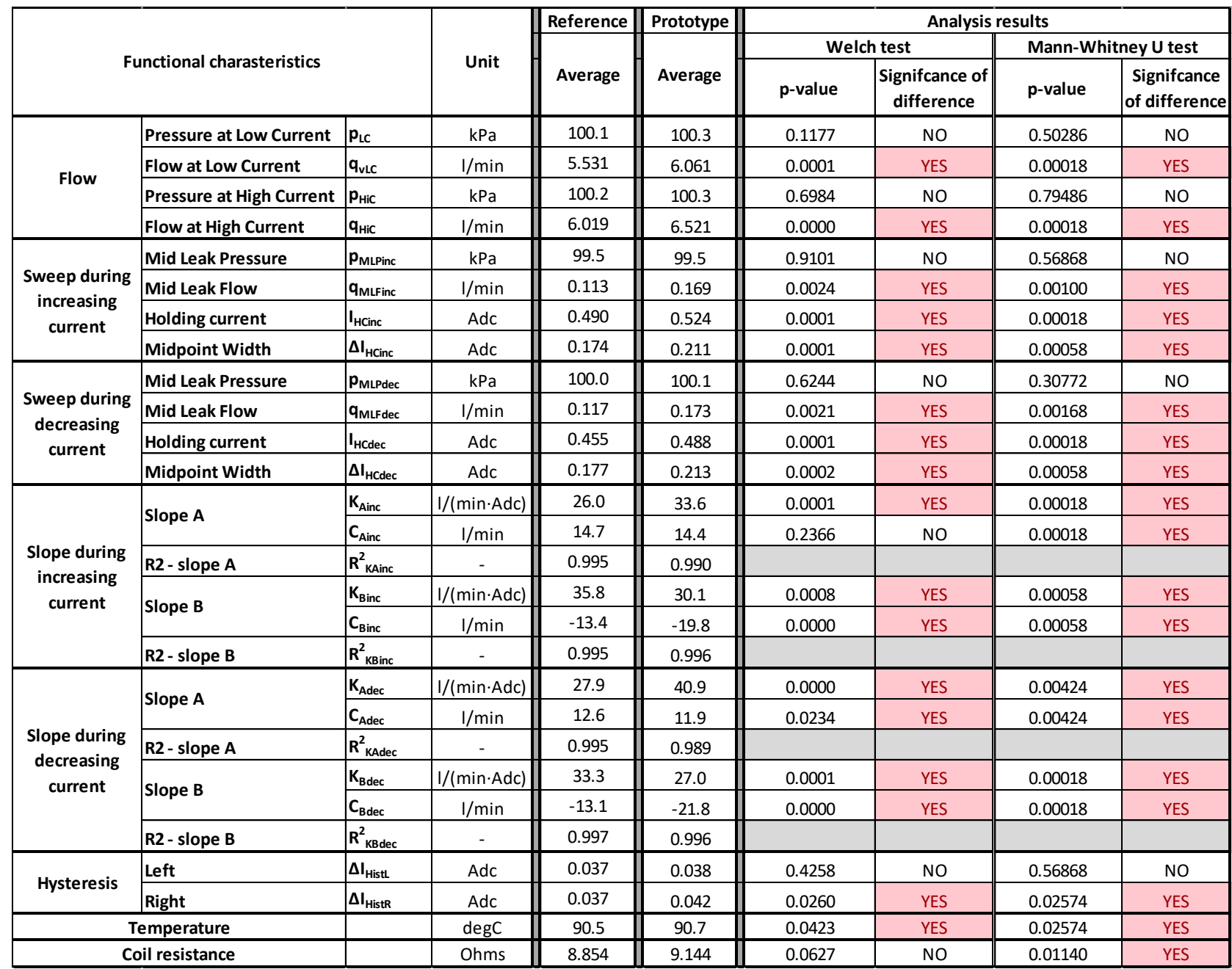

The measurements of volumetric flows, qvic, at low current levels and $q_{v L C}$ at high current levels (Fig. 8a), demonstrated the flows to be higher for the prototype valves by $>0.5 \mathrm{l} / \mathrm{min}$. vs. the flows for the OE valves (by $9.58 \%$ and $8.34 \%$, respectively). Since, during the tests, the oil pressures supplied to port $\mathrm{P}$ (Fig. 8b) were almost identical (approximately $100 \mathrm{kPa}$ ), it could be concluded that the prototype valves were characterised by lower flow resistance in comparison with the OE valves, which is their beneficial feature. A disadvantageous feature is the higher leaks of the prototype valves (Fig. 8c) in their neutral position (when ports A and B are cut off), both during control current increase, qmLFinc, and decrease, qmLFdec, by $49.6 \%$ and $47.7 \%$, respectively, when compared with the OE valves. However, comparing the leak values to flow, when a given port is open, the leak in the reference valve constitutes $2.2 \%$ of the full volumetric flow, while it is $2.8 \%$ in the prototype solenoid valve. This difference should not affect the proper operation of the VVTcontrol system. In addition, the prototype valves demonstrated higher current values necessary to maintain the neutral spool position both during control current increase, IHinc, and decrease, IHdec, which results in an extended width of the neutral spool position, $\Delta \mathrm{H}_{\text {Hinc }}$ and $\Delta \mathrm{H}_{\mathrm{Hde}} \mathrm{C}$, by $>20 \%$.
The comparative studies also indicated statistically significant differences in the values of directional coefficients for slopes $A$ (when port $A$ is opened) and $B$ (when port $B$ is opened), both directions of control current change. However, the directional coefficients for slope A were higher in the group of prototype valves than in the group of OE reference valves; the situation was reversed for slope $B$. The reference valves demonstrated lower divergences between the values of directional coefficients. The maximum difference value for OE valves is $7.6 \mathrm{l} /(\mathrm{min} \cdot \mathrm{A})$, while for the prototype valves, the maximum difference was $13.9 \mathrm{l} /(\mathrm{min} \cdot \mathrm{A})$. Higher differences in directional coefficient values may affect the quality of VVTcontrol. The prototype valves also had a bigger hysteresis on the 'right side' of flow; thus, they needed a bigger difference in the control current to change the state from opened port $B$ to neutral position. There may be a few reasons for the above-mentioned divergences: a difference in the resistance or inductance of the electromagnet coil (solenoid), different stiffness levels of the return springs or differences in the hydraulic solenoid valve geometry (a different overlap degree). The slight difference of approximately $0.3 \Omega$ in solenoid resistance indicates that it was caused by differences in wire diameter and the number of turns in the coil. 
a)
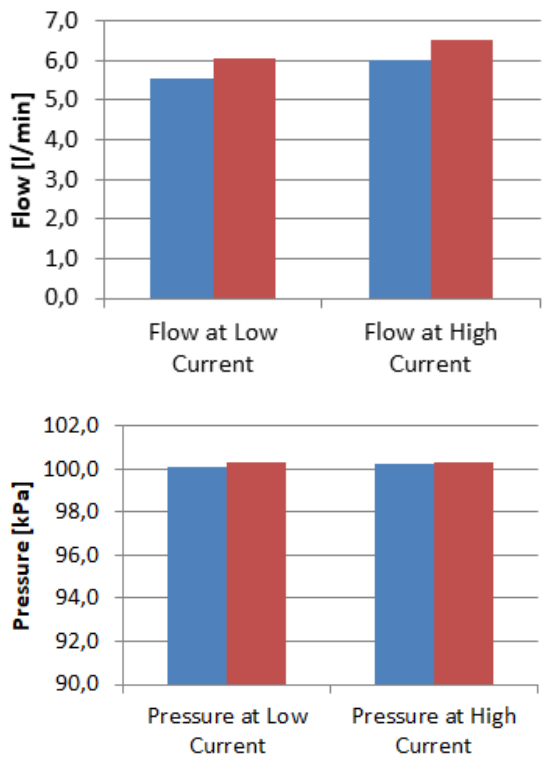

b)

neference valves $\quad$ Prototype valves

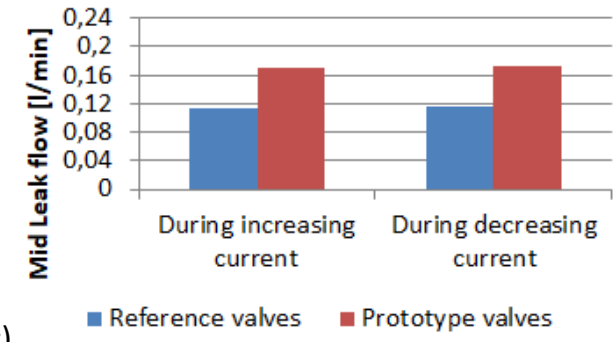

c)

Fig. 8. Comparison of main coefficients: a) flow at low and high current levels, b) pressure at low and high current levels,

c) oil leaks at neutral position

\section{SUMMARY}

The applied method of comparative studies of solenoid valve, based on two sample mean statistical tests, enabled a quality assessment of the engineering project by highlighting significant differences in functional-structural coefficients between 10 prototype products and 10 original solenoid valves; the latter were approached as benchmark products. The tests revealed several statistically significant differences in the coefficients between both groups of solenoid valves; nevertheless, the operational parameters of the prototype products fell within the tolerance limits, approved in the design objectives.

A significant flow resistance reduction, achieved in extreme solenoid valve spool positions and resulting in volumetric flow values $>8.5 \%$ higher, was a beneficial feature of the prototype design. The less advantageous features, identified during the statistical evaluation, may include higher leaks in the neutral spool position, higher divergences between the values of directional slope coefficients or increased hysteresis in the current required to maintain the neutral spool position. The differences identified among the parameters of tested valves constitute a valuable input research material for studies on design improvements of prototype VCT solenoid valves.
The performed tests demonstrated the suitability of the test stand for measurements and precise designation of operational parameters to meet the needs of control tests and quality assessments of solenoid valves used in VVT technology. However, it should be emphasised that a final evaluation of the effects exerted on combustion engine operation, resulting from changes, introduced to some functional utility coefficients of the solenoid valve, as of a sub-assembly of the control system, requires additional tests to be run on an engine testbed.

\section{REFERENCES}

1. Boguszewicz P., Czyż S. (2016), Influence of Valves Timing and Valves Lifts on Piston Engine Cylinder Filling (in Polish), Prace Instytutu Lotnictwa, 2016,3, 329-345.

2. Chauvin J., Petit N. (2007), Experimental control of variable cam timing actuators, IFAC Proceedings Volumes, Vol. 40, 10, 95-101.

3. D'Agostino R. B., Belanger A., D'Agostino R. B. Jr. (1990), A suggestion for using powerful and informative tests of normality, The American Statistician, Vol. 44, 4, 316-321.

4. Dresner T.,Barkan P. (1989), A review and classification of variable valve timing mechanisms, SAE Technical Paper 890674.

5. Gray C. (1988), A review of variable engine valve timing, $S A E$ Technical Paper 880386,

6. Hong H., Parvate-Patil G. B., Gordon B. (2004), Review and analysis of variable valve timing strategies - eight ways to approach, Proceedings of the Institution of Mechanical Engineers, Part D: Journal of Automobile Engineering, Vol. 218, 10, 1179-1200.

7. IATF 16949: 2016. Quality management system for organizations in the automotive industry.

8. INA-Schaeffler KG (2004), Testing Cam Phaser Systems, Technical publication, Germany

9. ISO-16750-1: 2006. Road vehicles - Environmental conditions and testing for electrical and electronic equipment, Part 1: General.

10. Jankovic M., Magner S. W. (2002), Variable cam timing: Consequences to automotive engine control design, IFAC Proceedings Volumes, Vol. 35, 1, 271-276.

11. Kanji G.P. (2006), 100 Statistical Tests, third ed., Sage Publications, London,

12. Kosuke N., Hiroyuki K.. Kazuya K. (2006), Valve timing and valve lift control mechanism for engines, Mechatronics, Vol. 16, 2, 121-129.

13. Marx A., Backes C., Meese E., Lenhof H. P., Keller A. (2016), EDISON-WMW: Exact dynamic programming solution of the WilcoxonMann-Whitney test, Genomics Proteomics Bioinformatics, Vol. 14, 1, 55-61.

14. Real statistics using Excel. http://www.real-statistics.com/testsnormality-and-symmetry/statistical-tests-normality-symmetry/dagostinopearson-test/ (accessed 29 July 2019)

15. Ren Z. (2011), System identification and control design for internal combustion engine variable valve timing systems, $\mathrm{PhD}$ Thesis, Michigan State University, Mechanical Engineering

16. Stein R., Galietti K., Leone T. (1995), Dual equal VCT - a variable camshaft timing strategy for improved fuel economy and emissions, SAE Technical Paper 950975.

17. Walpole R. E., Myers R. H., Myers S. L. (2012), Probability end statistics for engineers and scientists, ninth ed., Boston, Prentice-Hall.

18. Welch B. L. (1947), The generalization of "Student's" problem when several different population variances are involved, Biometrika, Vol. 34, 1-2, 28-35. 